\title{
Como os brasileiros escolhem os governadores? Desvendando as razões do voto para os executivos estaduais no Brasil em 2014
}

\author{
Oswaldo E. do Amaral \\ Marcela Tanaka
}

\section{Introdução ${ }^{1}$}

Em 2014, o Brasil realizou mais uma rodada de eleições gerais, a sexta desde o retorno do país à democracia. Com uma campanha presidencial bastante disputada e polarizada, a atenção dos analistas e da opinião pública ficou naturalmente concentrada sobre o prêmio maior: o Palácio do Planalto. No entanto, havia mais em jogo: vagas na Câmara e no Senado, nas Assembleias Legislativas e, em especial, 27 executivos estaduais, que foram disputados por 162 candidatos em todo o país (6,5 por vaga). Apesar de não terem o mesmo poder da presidência e de lidarem com orçamentos substantivamente menores do que o nacional, não há dúvida de que os governos estaduais se constituem em importante espaço de atuação e disputa política, em nível tanto local quanto nacional. É no âmbito estadual, por exemplo, que importantes parcelas das políticas públicas nas áreas de educação, saúde e segurança são elaboradas e executadas. Além disso, desde a redemocratização, todas as eleições presidenciais contaram com candidatos que tinham administrado executivos estaduais. Em 2006, 2010 e 2014, os candidatos à presidência pelo Partido da Social Democracia Brasileira (PSDB) que foram ao segundo turno, Geraldo Alckmin, José Serra e Aécio Neves, tinham governado, respectivamente, os estados de São Paulo e Minas Gerais.

Apesar da importância das disputas para os governos estaduais, pouco se sabe a respeito dos fatores que levam às escolhas dos eleitores para esses pleitos. O avanço que se verificou nos estudos eleitorais com dados tanto individuais quanto agregados sobre a corrida presidencial não foi acompanhado de trabalhos sistemáticos de abrangência nacional sobre as disputas estaduais - algo comum na ciência política internacional também (Remmer e Gélineau, 2005). É exatamente essa lacuna que este artigo busca começar a preencher. Existem fatores comuns que ajudam a explicar a escolha dos

\footnotetext{
${ }^{1}$ Este artigo foi realizado no âmbito do projeto "Organização e funcionamento da política representativa no estado de São Paulo (1994-2014)", financiado pela Fapesp (12/19330-8). Parte da pesquisa para este texto foi realizada no Instituto Kellogg da Universidade Notre Dame, em 2015, com financiamento do Programa Cooperação Mundial 2015 da Unicamp. Os autores agradecem à Unicamp e ao Instituto Kellogg pelo apoio financeiro e institucional e a Fernando Bizzarro Neto, a Guillermo Trejo, a Bruno Bolognesi, aos participantes do workshop "Eseb 2014", organizado pelo Cesop/Unicamp, e aos pareceristas de Opinião Pública pelas críticas e sugestões.
} 
eleitores em todo o país para os governos estaduais? Qual é o peso da avaliação do governo federal e da percepção sobre o desempenho da economia nas eleições nas unidades da federação? Candidatos de determinados partidos são beneficiados pela avaliação positiva do governo federal? A identidade partidária importa na hora de escolher os candidatos a governador? Essas são as perguntas que buscamos responder, ainda que de maneira preliminar, neste artigo. Para isso, realizamos análises multivariadas a partir dos dados de nível individual produzidos pelo Estudo Eleitoral Brasileiro (Eseb) de 2014. Os resultados demonstram que a preferência partidária, assim como nas eleições presidenciais, é importante elemento de escolha nos pleitos para os governos estaduais, e que a disputa entre PT e PSDB no plano nacional acaba por influenciar também o âmbito estadual.

Nos últimos anos, uma série de trabalhos, a partir de dados tanto agregados quanto individuais, buscou explicar os determinantes do voto nas eleições presidenciais no Brasil. Aproveitando-se de uma melhor organização e maior disponibilização dos dados eleitorais por meio do Tribunal Superior Eleitoral (TSE) e da realização de surveys mais frequentes, vários autores elucidaram importantes pontos sobre o comportamento eleitoral dos brasileiros. A avaliação de governo e a situação da economia, típicos elementos de um voto retrospectivo (Downs, 1999), foram apontados como fatores importantes nas escolhas para a presidência da República (Carreirão, 2002, 2007; Nicolau, 2007; Rennó, 2007; Holzhacker e Balbachevsky, 2007; Rennó e Cabello, 2010; Peixoto e Rennó, 2011; Nicolau, 2014a, 2014b; Amaral e Ribeiro, 2015). Alguns estudos demonstraram os efeitos da preferência partidária, ressaltando a importância dos partidos políticos na definição das escolhas eleitorais (Carreirão e Kinzo, 2004; Braga e Pimentel Jr, 2011; Ribeiro, Carreirão e Borba, 2011; Nicolau, 2014b; Amaral e Ribeiro, 2015).

A partir de dados eleitorais agregados, Hunter e Power (2007) e Nicolau e Peixoto (2007) indicaram o impacto dos programas sociais, em especial o Programa Bolsa Família (PBF), como responsáveis pela mudança na base social de apoio do presidente Luiz Inácio Lula da Silva em 2006. Zucco (2008, 2013), trabalhando com dados em nível municipal, chegou a conclusões semelhantes. Porém, adicionou que essas mudanças refletem muito mais o fenômeno do governismo - no qual eleitores de regiões mais pobres tendem a apoiar o governo -, do que uma transformação de longo prazo nas preferências políticas, como havia sugerido Singer (2009). Essa interpretação é parcialmente refutada por Limongi e Guarnieri (2015) por meio da análise dos dados por seções eleitorais. Segundo os autores, a alteração no padrão de votação do candidato Lula entre 2002 e 2006 não se mostra tão dramática quando o horizonte temporal é ampliado, e variáveis políticas, como a implosão da aliança entre o PSDB e o PFL antes das eleições de 2002, podem ter influenciado na penetração das candidaturas petistas na região Nordeste.

Embora os estados apareçam como peças importantes no xadrez político e eleitoral pós-regime autoritário no Brasil sob diferentes aspectos, seja no espaço legislativo (Abrucio, 1998; Samuels, 2003) ou na construção das candidaturas à presidência (Limongi 
e Cortez, 2010; Meneguello, 2011; Miranda, 2013; Mainwaring, Power e Bizzarro Neto, no prelo), há praticamente uma ausência de análises abrangentes, que busquem superar os limites dos estudos de caso, sobre o comportamento do eleitor no âmbito das disputas para os governos estaduais. Exceções importantes são o clássico trabalho de Lima Jr. (1983) sobre os subsistemas partidários estaduais e, mais recentemente, os trabalhos de Almeida e Carneiro (2008) e Bohn (2016). Utilizando-se de dados agregados relativos às eleições locais e gerais no período entre 1994 e 2000, Almeida e Carneiro encontram efeitos positivos das votações para prefeito e presidente sobre as votações para governador. Bohn, por sua vez, busca explicar as variações regionais no número de partidos a partir da combinação das abordagens institucionalista e sociológica.

Nos Estados Unidos, muitos trabalhos tentaram explicar o comportamento dos eleitores no plano subnacional e suas possíveis vinculações com aspectos econômicos e políticos de recorte nacional. De uma maneira geral, os estudos giram em torno do grau de responsabilização dos governos estaduais pelos eleitores. Ou seja, ao ir às urnas votar em pleitos estaduais, os eleitores estão de fato analisando a performance dos atuais governadores e seus respectivos partidos, ou estão reagindo a cenários nacionais, sobre os quais os executivos estaduais têm pouca influência? Essa questão é central para pensar a própria lógica do federalismo, pois, se os governadores e partidos não estão sendo avaliados por seu desempenho, mas sim pelo do presidente, isso colocaria em xeque a capacidade de controle dos cidadãos sobre os governos na esfera subnacional. De uma maneira geral, essa literatura trabalha sobre a "hipótese do referendo nacional", na qual as escolhas eleitorais no plano subnacional estariam subordinadas aos níveis de aprovação do presidente e de suas políticas (Simon, 1989; Simon, Ostrom e Marra, 1991). Atkeson e Partin (1995) sustentam, usando dados de nível individual, que os eleitores escolhem senadores e governadores a partir de lógicas distintas. A disputa para o Senado está vinculada à avaliação do desempenho do presidente e de suas políticas, enquanto a disputa para o governo depende da avaliação da economia estadual - argumento também defendido por Orth (2001). Carsey e Wright (1998) refutam em parte essa análise e afirmam que tanto a economia estadual quanto o nível de aprovação do presidente são importantes na decisão do voto para governador. Brown (2010), por sua vez, introduz a variável de identificação partidária como um importante elemento para compreender as avaliações dos governadores e de suas políticas feitas pelos eleitores. Seu argumento é o de que as avaliações que informam as escolhas eleitorais são influenciadas pelas preferências partidárias, não sendo, assim, plenamente "objetivas".

Partindo das questões levantadas para o caso estadunidense, alguns trabalhos tentaram verificar a "hipótese do referendo nacional" e a possibilidade de accountability vertical nas eleições subnacionais em outros contextos federativos. Remmer e Gélineau (2003; 2005), ao analisarem as eleições para os governos das províncias na Argentina, encontraram evidências de que a avaliação tanto do desempenho do governo nacional quanto de aspectos regionais impactam nas escolhas eleitorais subnacionais. Com um 
trabalho de recorte mais comparativo, Rodden e Wibbels (2010) analisam eleições subnacionais na Argentina, no Canadá, na Alemanha e nos EUA. Os autores não encontraram evidências de que os eleitores recompensam ou punem os candidatos aos governos subnacionais com base na performance econômica local. A pesquisa identificou, nos EUA e no Canadá, um impacto positivo na performance eleitoral de governadores do partido do presidente ou do primeiro-ministro quando a economia nacional apresenta forte crescimento.

Embora as perguntas levantadas pelos trabalhos elaborados sobre as eleições subnacionais nos EUA e em outros países sejam relevantes para o caso brasileiro, a transposição pura e simples dos mecanismos de análise se mostra inadequada, especialmente pela natureza dos sistemas partidários e das regras eleitorais. No Brasil, o sistema partidário é muito fragmentado, o que amplia o número de competidores. Além disso, a possibilidade de coligações entre os partidos para as disputas estaduais faz com que as estratégias das agremiações resultem em uniões entre partidos que estão em lados opostos no plano nacional, entre outras alternativas. Por fim, não dispomos no Brasil de surveys em vários estados com perguntas que permitam testar, em períodos eleitorais, as hipóteses trabalhadas no contexto norte-americano pelos trabalhos mencionados. O Estudo Eleitoral Brasileiro (Eseb), por exemplo, não conta com perguntas específicas sobre os governos estaduais, o que diminui as possibilidades de análise.

Este artigo busca dialogar, na medida das possibilidades e dos limites fornecidos pelos dados, com os dois grupos de literatura citados. Por um lado, queremos verificar se as variáveis que contribuem para explicar a decisão do eleitor no nível nacional também atuam no plano subnacional. Por outro, buscamos analisar se o caso brasileiro encontra paralelo com a literatura internacional no que toca ao impacto de fatores econômicos e políticos nacionais sobre a escolha do eleitor no nível estadual. Ao fazermos isso, tentamos, de maneira indireta, auxiliar na compreensão do funcionamento do sistema partidário brasileiro e complementar análises que identificaram os impactos da eleição para a presidência sobre os pleitos estaduais sob diferentes prismas, como os trabalhos de Almeida e Carneiro (2008) e Limongi e Cortez (2010).

Apesar de todas as dificuldades na utilização de dados de pesquisa nacional, acreditamos ser possível avançar no teste de hipóteses mais gerais sobre o comportamento do eleitor brasileiro nas disputas para os governos estaduais a partir das informações fornecidas pelo Eseb realizado em 2014. Nas próximas seções, apresentamos: os dados gerais das eleições para os 27 executivos estaduais, as hipóteses e as estratégias de análise adotadas em "As eleições de 2014 para os governos estaduais e a estratégia de análise"; os resultados dos modelos estatísticos em "Resultados"; e as "Considerações finais". 


\section{As eleições de 2014 para os governos estaduais e a estratégia de análise}

As 27 unidades da federação também realizaram eleições para o cargo de governador em 2014. Os partidos que mais receberam votos foram o PSDB $(26,63 \%$ dos votos válidos), o PMDB (23,30\%), o PT (22,74\%) e o PSB (7,37\%) (Tabela 1$)$. Juntos, seus candidatos obtiveram mais de $80 \%$ dos votos válidos em todo o país. Os quatro partidos foram também os que mais governadores elegeram. O PMDB venceu em sete estados (RS, RO, TO, ES, RJ, AL e SE), o PT, em cinco ( $A C, C E, P I, B A$ e MG), o PSDB, em cinco (PA, GO, MS, SP e PR) e o PSB, em três (PB, PE e DF) (Tabela 2). O equilíbrio entre PSDB, PT e PMDB no total de votos recebidos também pode ser verificado na importância das vitórias conquistadas por essas três legendas. Cada uma delas venceu em dois dos seis estados mais populosos do país.

Tabela 1

Número e porcentagem de votos válidos recebidos por partido para governador (10 turno, 2014)

\begin{tabular}{|l|c|c|}
\hline Partido & Total de votos & $\begin{array}{c}\text { \% de votos } \\
\text { válidos }\end{array}$ \\
\hline PSDB & 26.050 .143 & 26,63 \\
\hline PMDB & 22.796 .294 & 23,3 \\
\hline PT & 22.243 .721 & 22,74 \\
\hline PSB & 7.213 .040 & 7,37 \\
\hline Outros & 19.503 .805 & 19,96 \\
\hline Total & 97.836 .845 & 100 \\
\hline
\end{tabular}

Fonte: Elaboração própria com dados do TSE. 


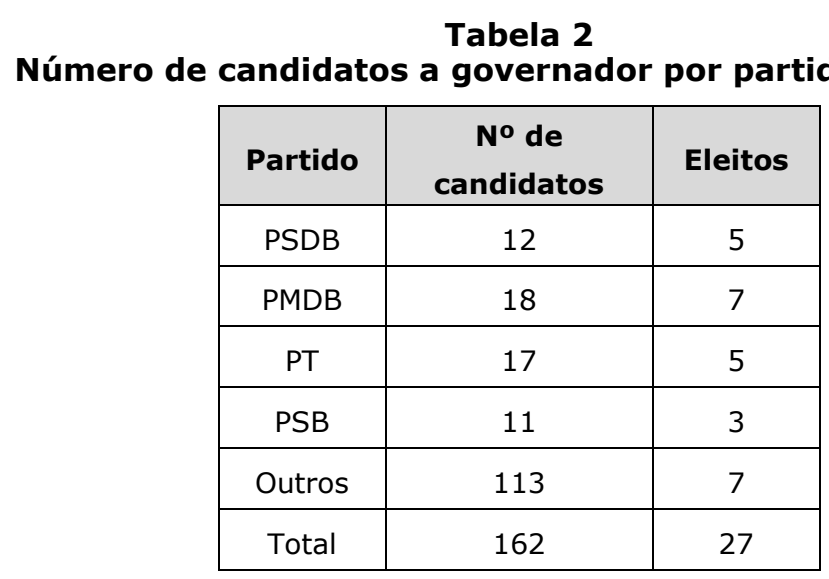

Fonte: Elaboração própria com dados do TSE

Apesar da concentração de votos, resultado do desempenho dos partidos citados em grandes colégios eleitorais, houve um aumento na dispersão de vitórias por partido no país. Em 2014, nove partidos venceram em pelo menos um estado. Essa dispersão, contudo, não foi acompanhada por um elevado nível de fragmentação no interior das unidades da federação. Nas últimas eleições, a média do número efetivo de candidatos foi de 2,55, mantendo-se próxima da verificada em 2010 (Melo, 2010; Mainwaring, Power e Bizzarro Neto, no prelo). Esses números explicam-se pela coordenação estratégica que existe envolvendo a disputa presidencial e as eleições estaduais. Partidos com pouca chance de vencer a disputa presidencial negociam com as agremiações com mais possibilidades de vitória o suporte a candidatos nos estados em troca de apoio no pleito para a presidência (Limongi e Cortez, 2010; Melo e Câmara, 2012).

Com o objetivo de encontrar explicações mais abrangentes do que as que se concentram em pura análise contextual para a decisão do eleitor nas disputas para os governos estaduais em todo o país, partimos das seguintes hipóteses, em parte derivadas das literaturas nacional e internacional mencionadas:

(a) As percepções sobre o desempenho do governo federal influenciam na decisão do eleitor nos pleitos subnacionais. Esperamos encontrar uma associação positiva entre a avaliação do governo federal e a decisão de votar em candidatos do PT e, inversamente, uma relação negativa entra a avaliação do governo federal e o voto nos candidatos do principal partido de oposição, o PSDB. Essa hipótese tem como base os trabalhos vinculados à ideia do "referendo nacional" e trata de verificar a existência, em nível individual, de possíveis efeitos do desempenho dos partidos na arena política nacional sobre as escolhas no plano subnacional.

(b) Como nas eleições presidenciais, a identidade política é importante na escolha para os governos estaduais. Imaginamos encontrar uma associação positiva da preferência, do 
voto nas eleições de 2010 e da escolha nas eleições presidenciais de 2014 com a decisão do eleitor nas disputas estaduais. Aqui, buscamos estender para os pleitos estaduais as análises realizadas por trabalhos como os de Carreirão e Kinzo (2004), Braga e Pimentel Jr. (2011), Ribeiro, Carreirão e Borba (2011), Nicolau (2014b) e Amaral e Ribeiro (2015), que identificaram o impacto das preferências partidárias na escolha do eleitor para as eleições presidenciais, e também, de maneira indireta, com o trabalho de Brown (2010), que trata dos impactos da identificação partidária nos pleitos para os executivos estaduais nos EUA.

(c) A percepção sobre o desempenho da economia impacta na decisão do eleitor nas disputas estaduais. Esperamos encontrar uma associação positiva entre a avaliação retrospectiva egotrópica e sociotrópica ${ }^{2}$ da economia e o voto nos candidatos à reeleição e nos que receberam apoio dos governadores em 2014 (tratados de maneira genérica aqui como incumbentes). Novamente, nossa hipótese se vincula à proposição do "referendo nacional". Aqui, porém, nosso trabalho se conecta mais diretamente à ideia do voto econômico (Downs, 1999) e dos seus impactos nas escolhas individuais, já identificados nos pleitos presidenciais no Brasil (Carreirão, 2002, 2007; Nicolau, 2007, 2014a, 2014b; Rennó, 2007; Holzhacker e Balbachevsky, 2007; Rennó e Cabello, 2010; Peixoto e Rennó, 2011; Amaral e Ribeiro, 2015), mas nunca analisados no plano estadual.

Para testarmos essas hipóteses, utilizamos o Estudo Eleitoral Brasileiro (Eseb) feito em 2014. O Eseb foi realizado pelo Centro de Estudos de Opinião Pública (Cesop) da Universidade Estadual de Campinas (Unicamp) em parceria com o Instituto Brasileiro de Opinião Pública e Estatística (Ibope). A série Eseb é realizada desde 2002 e faz parte do consórcio internacional Comparative Studies of Electoral Systems (CSES), coordenado pela Universidade de Michigan. O survey de 2014 contou com amostragem nacional de 2.506 entrevistas com eleitores ${ }^{3}$ e foi realizado entre os dias $1^{\circ}$ e 19 de novembro de 2014 . 0 processo de seleção da amostra foi feito em três estágios. No primeiro, os municípios foram selecionados probabilisticamente por meio do método PPT (Probabilidade Proporcional ao Tamanho), tomando como base o número de eleitores de cada município. A amostra foi estratificada por estado, e no caso de unidades da federação com regiões metropolitanas, foram subestratificadas em regiões metropolitanas e interior. No segundo, foram selecionados os setores censitários dentro de cada município, também pelo método PPT, e tendo como base o número de moradores de cada setor censitário. No terceiro, foi feita a seleção do entrevistado utilizando-se cotas proporcionais ao universo em função das

\footnotetext{
2 As avaliações egotrópica e sociotrópica estão ligadas ao papel do desempenho da economia na decisão do voto. A egotrópica é a que o eleitor faz de seu próprio bem-estar social. É uma avaliação econômica individual. A sociotrópica refere-se à do bem-estar social do país como um todo. Em resumo, é a avaliação da situação econômica do país. Especialmente nos EUA, uma série de autores tem se dedicado a investigar o papel dessas duas formas de avaliação da situação econômica na decisão do eleitor, tema caro à ciência política desde meados do século XX. Os trabalhos de Kramer (1971, 1983), Kinder e Kiewiet (1981), Weyland (1998) e Lewis-Beck (2006) discutem os impactos desses dois tipos de votos em diferentes épocas e contextos e avaliam sua pertinência para a compreensão do comportamento do eleitor.

3 O Eseb 2014 contou ainda com uma subamostra para o estado de São Paulo e o total de entrevistas foi de 3.136.
} 
seguintes variáveis: sexo, idade, escolaridade e ramo de atividade. A amostragem do Eseb permite, assim, análises de conjuntos específicos de estados, como a que fazemos aqui.

Para avaliarmos as hipóteses, construímos dois conjuntos de testes estatísticos a partir de regressões logísticas binomiais. O primeiro conta com uma análise das escolhas por partidos políticos. As variáveis dependentes foram o voto nos candidatos petistas, tucanos e peemedebistas para os governos estaduais, no primeiro turno, em 2014. A escolha dos três partidos para a análise deve-se a dois fatores: primeiro, foram os partidos que mais lançaram candidatos e que mais votos receberam nas eleições para os executivos estaduais em todo o país; segundo, os três partidos ocuparam posições diferentes no plano nacional no período entre 2011 e 2014, com o PT comandando a presidência da República, o PSDB como o principal partido de oposição e o PMDB como o principal sócio da coalizão governista, o que permite um maior controle sobre os efeitos encontrados. Separamos os eleitores desses partidos dos que escolheram outros candidatos. Em cada modelo, só consideramos os estados em que os partidos lançaram candidatos na cabeça da chapa ${ }^{4}$. A escolha por regressões logísticas binomiais deve-se ao fato de buscarmos identificar efeitos mais gerais sobre as escolhas dos eleitores nos candidatos desses partidos especificamente e ao fato de que apenas em cinco unidades da federação (GO, MS, PR, RO e SP), PT, PSDB e PMDB concorreram juntos, o que restringiria muito o universo de análise se adotássemos regressões logísticas multinomiais.

O segundo conjunto de testes conta com dois modelos e tem como variável dependente o voto no incumbente no primeiro turno das eleições de 2014. Sendo assim, separamos os eleitores que declararam ter votado no governador ou que optaram pelo candidato apoiado pelo governo dos que afirmaram ter votado em outros candidatos ${ }^{5}$. Em todos os modelos, inserimos as variáveis sociodemográficas "sexo", "escolaridade" e "idade".

\section{Resultados}

Apresentamos os resultados de acordo com os conjuntos de modelos especificados. Graficamente, mostramos as estimativas geradas pelos modelos para cada variável em relação às categorias de referência. As abas que aparecem nas figuras adiante indicam o índice de confiança de $95 \%$. Os resultados à direita de (1) indicam impacto positivo e, à esquerda, negativo. Se as abas cortarem o eixo, isso significa que os resultados não são estatisticamente significativos. Para facilitar a análise e a leitura, antes de cada modelo descrevemos as variáveis independentes utilizadas. Começamos pelos modelos que tratam de explicar o voto em candidatos ao governo estadual pelo PT, PSDB e PMDB. Esses modelos contemplam variáveis de três tipos: (a) avaliação retrospectiva do governo federal e da economia; (b) identidade política; e (c) variáveis sociodemográficas. Esses tipos são

\footnotetext{
${ }^{4}$ No Anexo 2 disponibilizamos a lista de estados em que PMDB, PSDB e PT apresentaram candidatos.

${ }^{5}$ No Anexo 1 disponibilizamos a lista dos partidos incumbentes e seus respectivos estados.
} 
comumente utilizados para explicar a decisão do eleitor tanto no Brasil quanto no exterior. Nesses três modelos contemplamos a avaliação retrospectiva do governo Dilma Rousseff (2011-2014), avaliações sociotrópicas e egotrópicas da economia e variáveis que mensuram a identidade política, como a preferência partidária e o voto para presidente em 2014.

Modelos 1, 2 e 3 - Votos em candidatos do PT (1), do PSDB (2) e do PMDB (3) para os governos estaduais em 2014.

V1 - Avaliação da situação econômica: criada a partir da pergunta: "Na sua opinião, a atual situação econômica do Brasil está melhor, igual ou pior do que há 12 meses?". As respostas foram agrupadas em três categorias: "Pior (0)", "Igual (1)" e "Melhor (2)". A categoria de referência foi "Pior".

V2 - Ascensão de classe social: construída a partir das perguntas em que os entrevistados respondiam se mudaram de classe social nos últimos oito anos, e se tinham mudado para melhor ou para pior. Separamos as respostas entre aqueles que responderam ter subido de classe (1) e os que afirmaram não ter subido ou ter descido de classe social (0). Os que responderam negativamente foram utilizados como a categoria de referência.

V3 - Beneficiário do Programa Bolsa Família: elaborada a partir da resposta à pergunta: "Nos últimos três anos, o(a) sr(a). ou alguém que vive em sua casa foi beneficiário (recebeu) do Programa Bolsa Família?". Os respondentes foram separados entre aqueles que receberam (1) e os que não receberam (0). Essa última categoria foi utilizada como referência.

V4 - Avaliação do governo Dilma: criada a partir da questão: "Na sua opinião, de uma maneira geral, o governo da presidente Dilma Rousseff nos últimos quatro anos foi ótimo, bom, ruim ou péssimo?". As respostas foram reunidas em três categorias: "Ruim/péssimo (0)", "Regular (1)" - resposta possível de maneira espontânea - e "Ótimo/Bom (2)". A categoria de referência utilizada foi "Ruim/Péssimo".

V5 - Voto para a presidência no primeiro turno em 2014: criada a partir da pergunta: "Em quem o(a) $\operatorname{sr}(a)$. votou para presidente no primeiro turno?", dividimos os respondentes entre aqueles que afirmaram ter votado em Dilma Rousseff (PT) (0), Aécio Neves (PSDB) (1) e Marina Silva (PSB) (2). A categoria de base utilizada foi o voto em Dilma.

V6 - Identificação partidária: elaborada a partir da questão: "Qual o partido o(a) $\operatorname{sr}(a)$. gosta?". Separamos as respostas entre aqueles que gostavam do PT (1), do PSDB (2), de outros partidos (3) e os que não gostavam de nenhuma legenda (0). A categoria de referência foi composta pelos que declararam não gostar de nenhum partido ${ }^{6}$. V7 - Sexo: feminino (1) e masculino (0). A categoria de referência foi masculino.

\footnotetext{
${ }^{6}$ No Eseb 2014, 32,8\% dos entrevistados afirmaram gostar de algum partido. O PT foi citado por $18 \%$ dos entrevistados e o PSDB, por 6,6\%. Optamos por não incluir os que se identificavam com o PMDB na análise devido ao baixo número de respostas ( 80 casos ou $3,2 \%$ ).
} 
V8 - Escolaridade: a partir da resposta dos entrevistados, criamos quatro grupos: "Fundamental Incompleto (0)", "Fundamental Completo/Médio Incompleto (1)", "Médio Completo/Superior Incompleto (2)" e "Superior Completo ou mais (3)". A categoria de referência foi "Fundamental Incompleto (0)".

V9 - Idade: variável contínua com a idade do entrevistado. 
Figura 1

Razões de chance associadas ao voto em candidatos do PT aos governos estaduais em 2014. Modelo de regressão logística

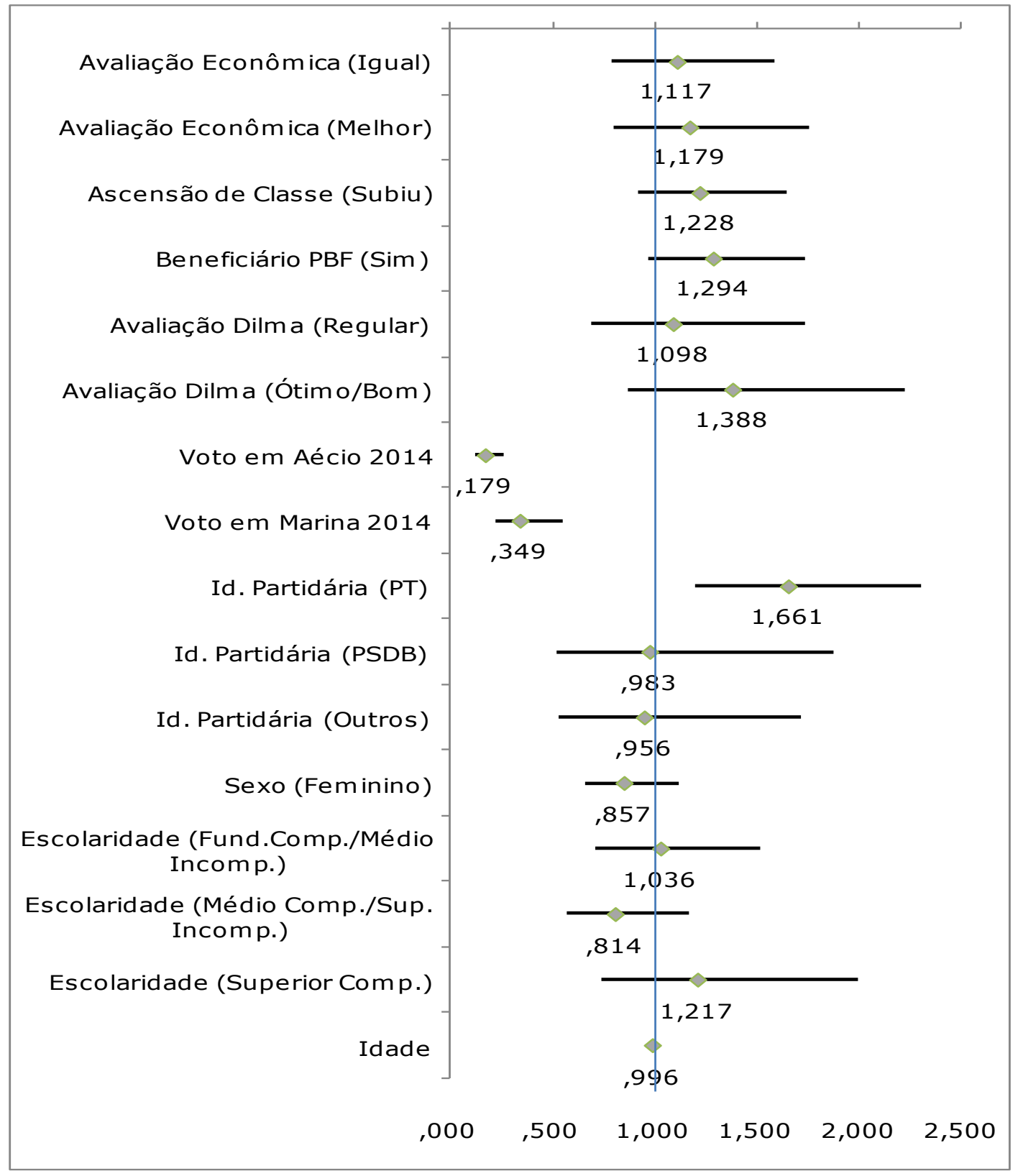

Fonte: Elaboração própria com dados do Eseb 2014.

$\mathrm{N}=1388$; Pseudo R2 Nagelkerke = ,245; -2Log likelihood $=1371,799 ; \%$ de acertos $=75,0 \%$. 
Figura 2

Razões de chance associadas ao voto em candidatos do PSDB aos governos estaduais em 2014. Modelo de regressão logística

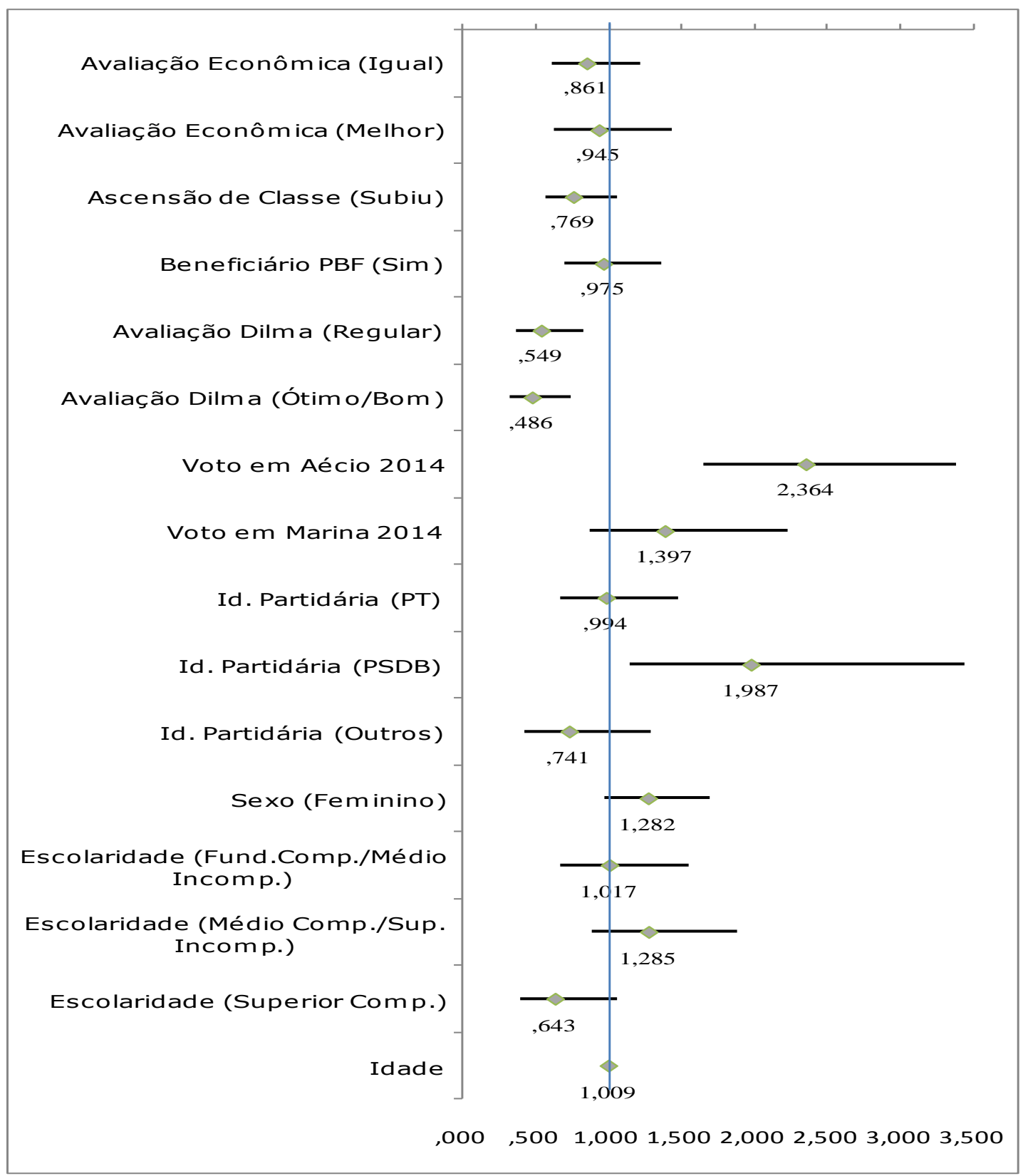

Fonte: Elaboração própria com dados do Eseb 2014.

$\mathrm{N}=926$; Pseudo R2 Nagelkerke = ,159; -2Log likelihood = 1160,674; $\%$ de acertos $=65,4 \%$. 
Figura 3

Razões de chance associadas ao voto em candidatos do PMDB aos governos estaduais em 2014. Modelo de regressão logística

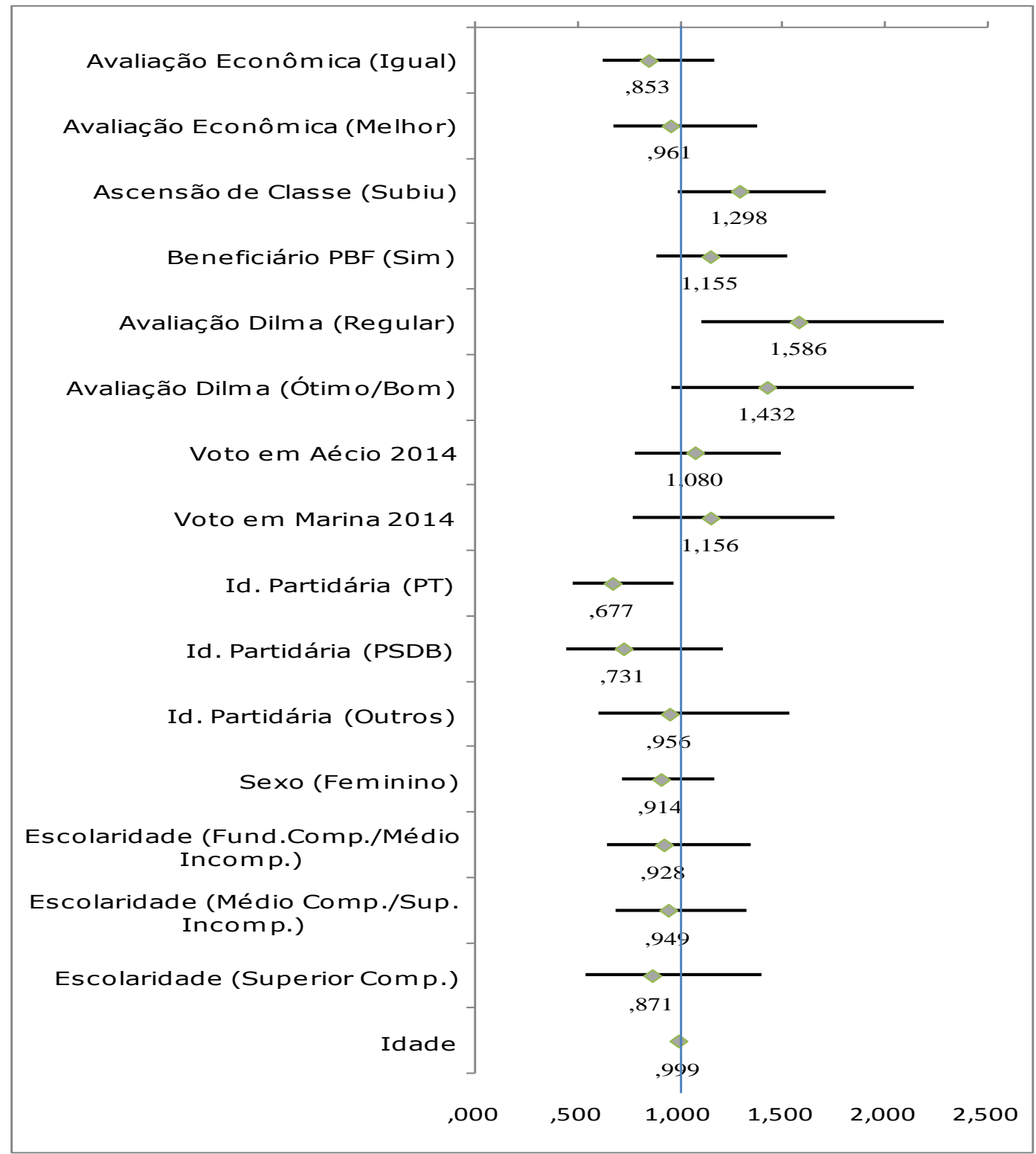

Fonte: Elaboração própria com dados do Eseb 2014.

$\mathrm{N}=1208$; Pseudo R2 Nagelkerke = ,016; -2Log likelihood $=1498,894 ; \%$ de acertos $=67,8 \%$.

Os resultados apontam que é possível identificarmos alguns aspectos comuns que ajudam a explicar a opção por candidatos do PT, do PSDB e do PMDB para os governos 
estaduais em todo o país. Ter votado em Aécio Neves ou em Marina Silva reduz as chances de escolher um candidato petista com relação àqueles que votaram em Dilma Rousseff. Como esperado, identificar-se com o PT amplia a chance de voto em postulantes aos governos estaduais desse partido com relação àqueles que não preferem nenhuma agremiação (Figura 1). Com relação aos candidatos tucanos, avaliar o governo federal como "regular" ou "ótimo/bom" reduz as chances de voto em comparação com aqueles que apontaram o governo como "ruim/péssimo". Ou seja, avaliações negativas do governo Dilma Rousseff ampliam as chances de escolha em candidatos do PSDB. Também como esperado, ter votado em Aécio Neves nas eleições presidenciais e se identificar com o PSDB aumentam as chances de escolher candidatos tucanos (Figura 2). Já a análise com relação à escolha em candidatos do PMDB é menos conclusiva. Apenas avaliar o governo Dilma Rousseff como "regular" e identificar-se com o PT exerceram impacto significativo, positivamente e negativamente, respectivamente, na opção por postulantes peemedebistas aos governos estaduais (Figura 3 ).

Esses dados apontam que a identificação partidária importou na escolha para os governos estaduais, assim como aconteceu na disputa presidencial em 2014 (Amaral e Ribeiro, 2015). Os modelos também sugerem que a disputa entre PT e PSDB no plano nacional parece exercer algum efeito estruturador também no âmbito estadual. Ter escolhido Dilma Rousseff ou Aécio Neves na disputa presidencial impactou nas escolhas de candidatos petistas e tucanos nos pleitos para os governos estaduais. Já o impacto da avaliação do governo federal apresentou resultados menos nítidos sobre as escolhas de candidatos de PT, PSDB e PMDB no plano estadual. Ter uma avaliação positiva do governo federal nos últimos quatro anos não apresentou resultado estatisticamente significativo nas escolhas por candidatos petistas, mas reduziu as chances de voto em candidatos do PSDB.

Ainda com relação a esse primeiro conjunto de modelos, é importante observar que a variável "Beneficiário do PBF", apesar de ter violado o intervalo de confiança estabelecido (95\%) e não ser estatisticamente significativa, trouxe resultados interessantes. Ser beneficiário do PBF apresentou resultados positivos no modelo que busca explicar a escolha por candidatos petistas. Como a violação dos parâmetros do intervalo de confiança foi pequena, o que poderia ter sido alterado caso o número de entrevistados fosse maior, existe um indicativo sutil de que candidatos petistas podem ter se beneficiado de uma percepção positiva sobre políticas praticadas pelo governo petista no âmbito federal, como as que resultaram no aumento da renda nos anos anteriores a 2014 e o próprio PBF. Voltaremos a esses resultados nas "Considerações finais".

Conforme mencionamos, seguimos agora para os dois modelos em que avaliamos as explicações para os votos nos incumbentes nas eleições para os governos estaduais em todo o país em 2014. Nesses modelos consideramos variáveis de quatro tipos: (a) avaliação da situação econômica; (b) avaliação de governo e de políticas públicas; (c) identidade política; e (d) variáveis sociodemográficas. Com relação ao primeiro grupo, incluímos variáveis de avaliação sociotrópica e egotrópica da situação econômica. $O$ 
segundo tipo conta com elementos de avaliação do governo federal e de políticas públicas de recorte estadual nas áreas de saúde, educação e segurança ${ }^{7}$. O terceiro tipo conta com a identificação partidária e com a declaração de voto para governador em 2010 e para presidente em 2014. O modelo 5 apresenta também um controle por efeitos fixos nos estados. O controle foi feito por meio de variáveis dummies para cada unidade da federação com o objetivo de observar possíveis efeitos contextuais sobre os modelos.

Modelos 4 e 5 - Votos em candidatos à reeleição ou apoiados pelos governadores (incumbentes)

V1 - Avaliação da situação econômica: construída a partir da pergunta: "Na sua opinião, a atual situação econômica do Brasil está melhor, igual ou pior do que há 12 meses?". As respostas foram agrupadas em três categorias: "Pior (0)", "Igual (1)" e "Melhor (2)". A categoria de referência foi "Pior".

V2 - Ascensão de classe social: criada a partir das perguntas em que os entrevistados respondiam se mudaram de classe social nos últimos oito anos, e se tinham mudado para melhor ou para pior. Separamos as respostas entre aqueles que responderam ter subido de classe (1) e os que afirmaram não ter subido ou ter descido de classe social (0). Os que responderam negativamente foram utilizados como a categoria de referência.

V3 - Beneficiário do Programa Bolsa Família: elaborada a partir da resposta à pergunta: "Nos últimos três anos, o(a) sr(a). ou alguém que vive em sua casa foi beneficiário (recebeu) do Programa Bolsa Família?". Os respondentes foram separados entre aqueles que receberam (1) e os que não receberam (0). Essa última categoria foi utilizada como referência.

V4 - Avaliação do governo Dilma: composta a partir da questão: "Na sua opinião, de uma maneira geral, o governo da presidente Dilma Rousseff nos últimos quatro anos foi ótimo, bom, ruim ou péssimo?". As respostas foram reunidas em três categorias: "Ruim/Péssimo (0)", "Regular (1)" - possível de maneira espontânea - e "Ótimo/Bom (2)". A categoria de referência utilizada foi "Ruim/Péssimo".

V5 - Avaliação do controle da criminalidade: criada a partir da pergunta: "Vou citar algumas políticas e gostaria que o(a) sr(a). utilizasse essa escala para me dizer o quanto está satisfeito com cada uma delas. Que nota de 0 a 10 você dá para sua satisfação em relação ao controle de criminalidade?". Variável contínua de 0 a 10.

V6 - Avaliação da qualidade do ensino público: elaborada a partir da pergunta: "Vou citar algumas políticas e gostaria que o(a) $\operatorname{sr}(a)$. utilizasse essa escala para me dizer o quanto

\footnotetext{
${ }^{7}$ As variáveis 5, 6 e 7 nesses modelos foram inseridas como forma de controlar eventual existência de responsabilização pela execução de políticas públicas com forte participação dos estados. Em 2009, os estados foram responsáveis por $82 \%$ dos gastos na área de segurança, 38,2\% na de educação e 35,9\% na de saúde. A União, por sua vez, foi a responsável por 13\%, 18,4\% e 15,3\% em cada área, respectivamente (Afonso et al., 2012).
} 
está satisfeito com cada uma delas. Que nota de 0 a 10 você dá para sua satisfação em relação à qualidade do ensino público?". Variável contínua de 0 a 10.

V7 - Avaliação do acesso aos serviços de atendimento médico: criada a partir da pergunta: "Vou citar algumas políticas e gostaria que o(a) sr(a). utilizasse essa escala para me dizer o quanto está satisfeito com cada uma delas. Que nota de 0 a 10 você dá para sua satisfação em relação ao acesso aos serviços médicos?". Variável contínua de 0 a 10.

V8 - Identificação com o partido do incumbente: criada a partir da resposta dos entrevistados à pergunta: "De qual partido o(a) sr(a). gosta?". Os respondentes foram separados entre aqueles que se identificavam com o partido do incumbente (1) e os que não se identificavam (0). A última categoria foi utilizada como a de referência.

V9 - Voto no incumbente em 2010: criada a partir da resposta à pergunta: "E para governador em quem o(a) sr(a). votou no primeiro turno em 2010?". Separamos as respostas entre aqueles que declararam ter votado nos candidatos dos partidos dos incumbentes (no ano de 2014) em 2010 (1) e aqueles que votaram em outros candidatos (0). A categoria de referência foi este último grupo.

V10 - Voto para a presidência no primeiro turno em 2014: composta a partir da pergunta: "Em quem o(a) sr(a). votou para presidente no primeiro turno?", dividimos os respondentes entre aqueles que afirmaram ter votado em Dilma Rousseff (PT) (0), Aécio Neves (PSDB) (1) e Marina Silva (PSB) (2). A categoria de base utilizada foi o voto em Dilma.

V11 - Sexo: feminino (1) e masculino (0). A categoria de referência foi masculino.

V12 - Escolaridade: construída a partir da resposta dos entrevistados, criamos quatro grupos: "Fundamental Incompleto (0)", "Fundamental Completo/Médio Incompleto (1)", "Médio Completo/Superior Incompleto (2)" e "Superior Completo ou mais (3)". A categoria de referência foi "Fundamental Incompleto (0)".

V13 - Idade: variável contínua com a idade do entrevistado. 
Figura 4

Razões de chance associadas ao voto nos "incumbentes" nas eleições para os governos estaduais em 2014. Modelo de regressão logística

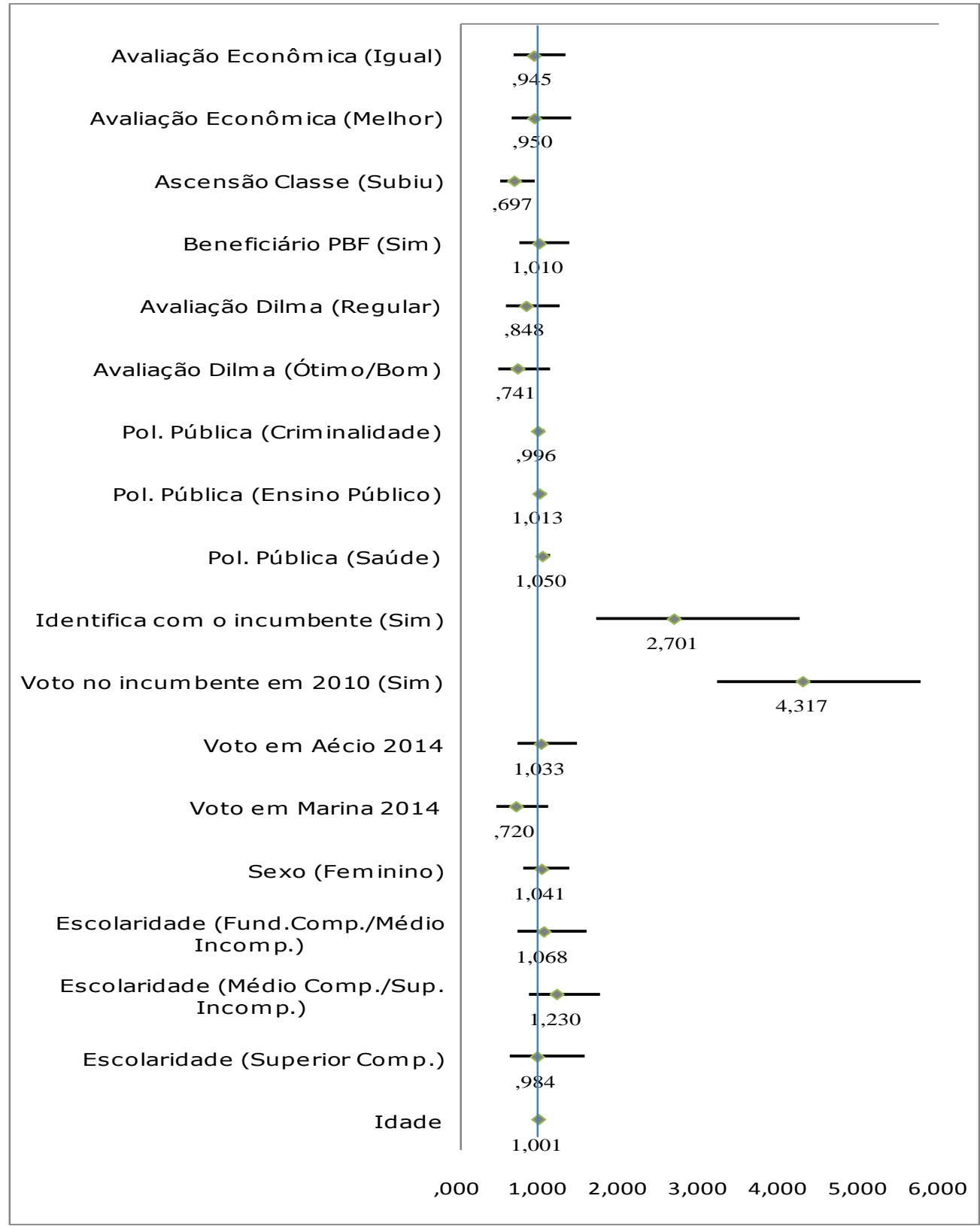

Fonte: Elaboração própria com dados do Eseb 2014.

$\mathrm{N}=1049 ;$ Pseudo R2 Nagelkerke = ,192; -2 Log likelihood $=1278,436 ; \%$ de acertos $=67,7 \%$. 
Figura 5

Razões de chance associadas ao voto nos "incumbentes" nas eleições para os governos estaduais em 2014. Modelo de regressão logística com efeitos fixos

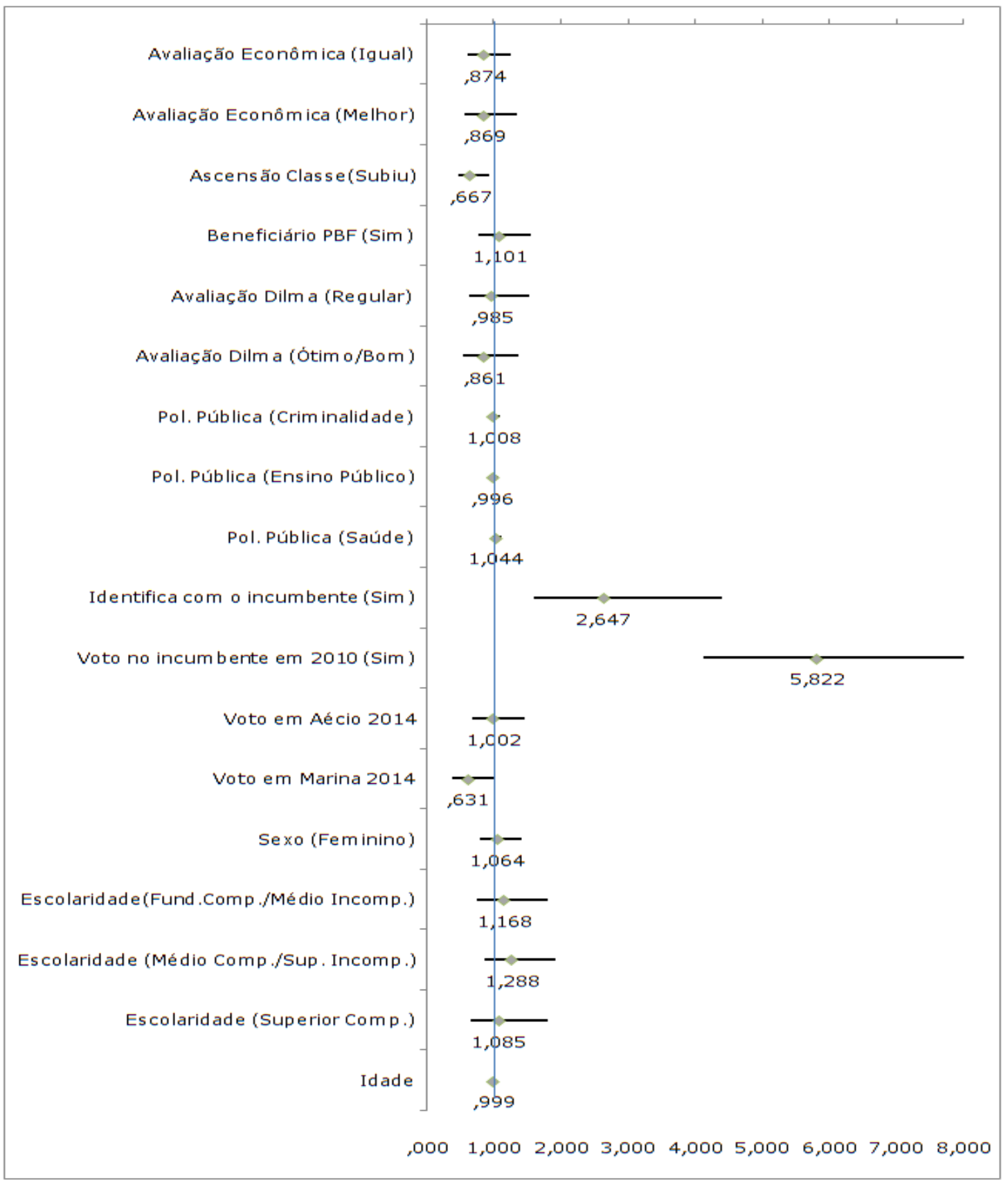

Fonte: Elaboração própria com dados do Eseb 2014.

$\mathrm{N}=1049 ;$ Pseudo R2 Nagelkerke = ,330; -2 Log likelihood = 1143,541; \% de acertos $=72,7 \%$. 
Os modelos 4 e 5 confirmam alguns dos achados encontrados nas análises anteriores. Em ambos, identificar-se com o partido do candidato da situação amplia em quase três vezes a chance de votar nele. De forma semelhante, ter votado no incumbente em 2010 amplia substancialmente a chance de escolher o próprio candidato à reeleição ou o indicado pelo governador para sucedê-lo. Isso demonstra a existência de uma razoável estabilidade na escolha dos eleitores para os pleitos estaduais.

É importante notar que as variáveis usadas nos modelos sobre a avaliação retrospectiva da situação econômica explicam muito pouco sobre a decisão do eleitor de votar ou não nos candidatos definidos como incumbentes. A avaliação do desempenho da economia nos últimos 12 meses e ser beneficiário do PBF não se mostraram estatisticamente significativas para explicar a escolha do eleitor em nenhum dos modelos. Ter subido de classe, por sua vez, apresentou resultado negativo. De uma maneira geral, os resultados sobre a avaliação econômica indicam que os eleitores, ao irem às urnas para escolher os governadores, não recompensam ou punem os incumbentes a partir de avaliações gerais da situação econômica.

Por fim, devemos destacar que as avaliações do governo federal e de políticas públicas nas áreas de combate à criminalidade, educação e saúde não apresentaram resultados estatisticamente significativos em ambos os modelos. Esse é um dado que deve ser observado com cuidado. Com relação à avaliação do desempenho do governo federal, é possível afirmarmos que os incumbentes pareceram não se beneficiar de percepções positivas da administração Dilma Rousseff. Já com relação à satisfação com as políticas públicas, é mais difícil fazer afirmações definitivas, pois as perguntas não eram específicas sobre a atuação dos governos estaduais, e muitas dessas áreas apresentam sobreposição de competências entre união, estados e municípios.

\section{Considerações finais}

Neste artigo buscamos desvendar algumas das razões para as escolhas dos eleitores nas disputas pelos governos estaduais no Brasil. Partimos de hipóteses derivadas das literaturas nacional e internacional sobre alguns dos determinantes do comportamento eleitoral nos pleitos presidenciais e para os executivos estaduais. A primeira delas apontava para o impacto do desempenho do governo federal sobre as disputas estaduais. A segunda, para o papel de preferências políticas e partidárias na hora de o eleitor escolher seu candidato a governador de estado. A terceira, para a influência das percepções sobre a economia de uma forma geral sobre a decisão do eleitor no âmbito subnacional.

Nossos resultados confirmam em parte as hipóteses levantadas. Não encontramos evidências de que a percepção sobre o desempenho da economia seja capaz de influenciar os eleitores na hora de escolherem um candidato a governador. Incumbentes, seja o próprio governador ou um candidato por ele apoiado, não se beneficiam de uma percepção 
positiva sobre a economia. O mesmo aconteceu quando analisamos os resultados para candidatos do PT, do PSDB e do PMDB.

Já as percepções sobre o desempenho do governo federal apresentaram algumas evidências de que é possível que o eleitor tome decisões no plano estadual observando o que acontece no plano nacional, o que está de acordo com o que parte da literatura internacional afirma sobre o tema (Carsey e Wright, 1998; Remmer e Gélineau, 2005). Eleitores que avaliaram o governo de Dilma Rousseff como "regular" e "ótimo/bom" apresentaram menos chances de escolher candidatos do PSDB, principal partido de oposição, quando tomamos por referência aqueles que avaliaram o governo como "ruim/péssimo". Além disso, encontramos sutil evidência de que o PBF pode ter beneficiado candidatos petistas nessas disputas, o que poderia indicar que o programa se constituiu em uma marca do Partido dos Trabalhadores e que seus benefícios eleitorais podem ir além da disputa pela presidência.

Com relação à segunda hipótese, encontramos evidências de que a preferência partidária exerce impacto nas disputas estaduais, assim como ocorre na disputa presidencial. Identificar-se com o PT amplia em $66 \%$ a chance de escolher de um candidato petista a governador. Preferir o PSDB amplia em 98\% a chance de optar por um tucano. De maneira semelhante, preferir o partido do incumbente aumenta em muito a chance de optar por ele (mais de $160 \%$ nos dois modelos).

Encontramos também algum grau de coerência do eleitor tanto com relação à sua escolha anterior para a disputa estadual quanto com relação à sua opção para a presidência da República. Ter votado no governador em 2010 aumenta em mais de 300\%, no primeiro modelo, e em mais de $450 \%$, no segundo, as chances de escolher o candidato da situação no pleito de 2014. Já ter escolhido a candidata Dilma Rousseff para a presidência nas eleições de 2014 amplia as chances de escolher de candidatos petistas para os governos estaduais. De maneira semelhante, ter optado pelo tucano Aécio Neves aumenta as chances de escolher candidatos do PSDB.

Por fim, é importante destacarmos que não encontramos evidências suficientes de que os eleitores tomam suas decisões com base em avaliações de políticas públicas específicas, como o combate à criminalidade, a qualidade do ensino público e o acesso a serviços de atendimento médico. Esse é um dado relevante que coloca em xeque a efetividade do accountability vertical no caso dos governos estaduais e está de acordo com os achados de Remmer e Gélineau (2005) sobre o caso argentino e de Rodden e Wibbels (2010) em sua análise comparativa envolvendo os EUA, o Canadá e a Argentina. No entanto, esse dado deve ser obervado com cuidado já que as perguntas não estabeleciam vinculação entre essas políticas públicas e os governos estaduais. São necessárias aqui mais análises com perguntas específicas sobre esse tema.

Diante dos resultados encontrados, é possível afirmarmos que existem alguns elementos mais gerais que ajudam a estruturar a preferência dos eleitores nas disputas pelos governos estaduais em todo o país. Ou seja, esses pleitos não são regidos 
exclusivamente por lógicas contextuais das unidades da federação. As preferências partidárias e a estruturação da competição política no nível presidencial, em que PT e PSDB protagonizaram as últimas seis disputas (1994, 1998, 2002, 2006, 2010 e 2014), também fazem parte do jogo, demonstrando que as escolhas eleitorais no plano subnacional também estão associadas à disputa e ao desempenho dos partidos no plano nacional. Isso significa que não há descolamento entre os dois níveis de disputa - nacional e estadual não só no que toca às estratégias partidárias (Almeida e Carneiro, 2008; Limongi e Cortez, 2010; Melo e Câmara, 2012; Limongi e Vasselai, 2016), mas também na cabeça do eleitor.

Oswaldo E. do Amaral - Professor do Programa de Pós-Graduação em Ciência Política da Unicamp e pesquisador do Cesop/Unicamp. E-mail: <oswamaral@gmail.com>.

Marcela Tanaka - Mestranda em Ciência Política na Unicamp e pesquisadora do Grupo de Estudos de Política Brasileira (Polbras) do Cesop/Unicamp.

E-mail: <marcela.tanaka@hotmail.com>.

\section{Referências bibliográficas}

ABRucio, F. L. Os barões da federação: os governadores e a redemocratização brasileira. São Paulo: Hucitec, 1998.

Afonso, J. R., et al. In: Brosio, G.; Jiménez, J. P (eds.). Decentralization and reform in Latin America. Cheltenham: Edward Elgar/Cepal, 2012.

Almeida, M. H. T.; CARneiro, L. P. "Definindo a arena política local: sistemas partidários municipais na federação brasileira". Dados, vol. 51, no 2, p. 403-432, 2008.

Amaral, O. E.; Ribeiro, P. F. "Por que Dilma de novo? Uma análise exploratória do Estudo Eleitoral Brasileiro de 2014". Revista de Sociologia e Política, vol. 23, no 56, p. 107-123, 2015.

ATKESON, L. R.; PARTIN, R. W. "Economic and referendum voting: a comparison of gubernatorial and senatorial elections". American Political Science Review, vol. 89, no 1, p. 99-107, 1995.

BoHN, S. "Institutional, societal and economic determinants of party system size: evidence from Brazil". International Political Science Review, vol. 37, no 1, p. 3-17, 2016.

Braga, M. S. S.; Pimentel JR., J. "Os partidos políticos brasileiros realmente não importam?". Opinião Pública, vol. 17, no 2, p. 271-303, 2011.

BRown, A. "Are governors responsible for the state economy? Partisanship, blame and divided federalism". The Journal of Politics, vol. 72, no 3, p. 605-615, 2010.

CARreirÃo, Y. S. A decisão de voto nas eleições presidenciais brasileiras. Florianópolis/Rio de Janeiro: Editora da UFSC/FGV, 2002.

"Identificação ideológica, partidos e voto na eleição presidencial de 2006". Opinião Pública, vol. 13, no 2, p. 307-339, 2007.

CARreirÃo, Y. S.; Kinzo, M. D. "Partidos políticos, preferência partidária e decisão eleitoral no Brasil (1989/2002)". Dados, vol. 47, no 1, p. 131-168, 2004. 
CARSEY, T. M.; WRIGHT, G. C. "State and national factors in gubernatorial and senatorial elections". American Journal of Political Science, vol. 42, p. 994-1002, 1998.

Downs, A. Uma teoria econômica da democracia. São Paulo: Edusp, 1999.

HolzhaCKer, D.; BALBACheVsky, E. "Classe, ideologia e política: uma interpretação dos resultados das eleições de 2002 e 2006". Opinião Pública, vol. 13, no 2, p. 283-306, 2007.

Hunter, W.; Power, T. "Rewarding Lula: Executive Power, social policy, and the Brazilian elections of 2006". Latin American Politics and Society, vol. 49, no 1, p. 1-30, 2007.

KRAMER, G. H. "Short-term fluctuations in U.S. voting behavior, 1896-1964". The American Political Science Review, vol. 65, no 1, p. 131-143, 1971.

. "The ecological fallacy revisited: aggregate-versus individual level findings on economics and $\overline{\text { elections, }}$ and sociotropic voting". The American Political Science Review, vol. 77, no 1, p. 92-111, 1983.

KInder, D. R.; KIEWIET, D. R. "Sociotropic politics: the American case". British Journal of Political Science, vol. 11, no 2, p. 129-161, 1981.

LEWIS-BECK, M. S. "Does economics still matter? Econometrics and the vote". The Journal of Politics, vol. 68, no $^{\circ}$, p. 208-212, 2006.

LimA JUNIOR, O. B. Os partidos políticos brasileiros - A experiência federal e regional: 1945/64. Rio de Janeiro: Graal, 1983.

Limongi, F.; CoRtez, R. "As eleições de 2010 e o quadro partidário". Novos Estudos, no 88, p. 21-37, 2010.

Limongi, F.; Guarnieri, F. "Competição partidária e voto nas eleições presidenciais no Brasil". Opinião Pública, vol. 21, no 1, p. 60-86, 2015.

LIMONGI, F.; VASSELAI, F. "Coordenando candidaturas: coligações e fragmentação partidária nas eleições gerais brasileiras". In: Anais do X Encontro da ABCP, Belo Horizonte, 2016.

Mainwaring, S.; Power, T. J.; Bizzarro Neto, F. The uneven institutionalization of a party system: Brazil. In: MAINWARING, S. (ed.). Party systems in Latin America: institutionalization, decay, and collapse. Cambridge: Cambridge University Press, p. 1-54, no prelo.

Melo, C. R. "Eleições presidenciais, jogos aninhados e sistema partidário no Brasil". Revista Brasileira de Ciência Política, no 4, p. 13-41, 2010.

Melo, C. R.; CÂMARA, R. "Estrutura de competição pela presidência e consolidação do sistema partidário no Brasil". Dados, vol. 55, no 1, p. 71-117, 2012.

Meneguello, R. "Las elecciones de 2010 y los rumbos del sistema de partidos brasileño. Política nacional, fragmentación y lógica de coaliciones". In: SÁEZ, M. A.; TAGinA, M. L. (eds.). América Latina: política y elecciones del bicentenario (2009-2010). Madrid: Centro de Estudios Politicos y Constitucionales, p. 449-497, 2011.

MiRANDA, G. "Coligações eleitorais: tendências e racionalidades nas eleições federais e majoritárias estaduais (1990-2010)". Revista de Sociologia e Política, vol. 21, no 47, p. 69-90, 2013.

Nicolau, J. "An analysis of the 2002 presidential elections using logistic regression". Brazilian Political Science Review, vol. 1, no 1, p. 125-135, 2007. 
COMO OS BRASILEIROS ESCOLHEM OS GOVERNADORES?

NicolaU, J. Vermelhos e azuis: um estudo sobre os determinantes do voto nas eleições presidenciais brasileiras (2002-2010)". In: Anais do IX Encontro da ABCP, Brasília, DF, 2014a.

"Determinantes do voto no primeiro turno das eleições presidenciais brasileiras de 2010: uma análise exploratória". Opinião Pública, vol. 20, no 3, p. 311-325, 2014b.

Nicolau, J.; PeiXoto, V. "Uma disputa em três tempos: uma análise das bases municipais das eleições presidenciais de 2006". In: Anais do 31 Encontro Anual da Anpocs, Caxambu, MG, 2007.

ORTH, D. A. "Accountability in a federal system: the governor, the president, and economic expectations". State Politics and Policy Quartely, no 1, p. 412-432, 2001.

Peixoto, V.; Rennó, L. "Mobilidade social ascendente e voto: as eleições presidenciais de 2010 no Brasil". Opinião Pública, vol. 17, no 2, p. 304-332, 2011.

Remmer, K.; Gélineau, F. "Subnational electoral choice economic and reerendum voting in Argentina, 1983-1999". Comparative Political Studies, vol. 36, no 7, p. 801-821, 2003.

"Political decentralization and electoral accountability: the Argentine experience, 1983-

2001". British Journal of Political Science, vol. 36, p. 133-157, 2005.

Rennó, L. "Escândalos e voto: as eleições presidenciais brasileiras de 2006". Opinião Pública, vol. 13, no 2, p. 260-282, 2007.

Rennó, L.; CABello, A. "As bases do lulismo: a volta do personalismo, realinhamento ideológico ou não alinhamento?". Revista Brasileira de Ciências Sociais, vol. 25, no 74, p. 39-60, 2010.

Ribeiro, E.; CARreirão, Y. S.; BorbA, J. "Sentimentos partidários e atitudes políticas entre os brasileiros". Opinião Pública, vol. 17, no 2, p. 336-368, 2011.

RodDen, J.; WibBeLS, E. "Dual accountability and the nationalization of party competition: evidence from four federations". Party Politics, vol. 16, p. 1-25, 2010.

Samuels, D. Ambition, federalism, and legislative politics in Brazil. Cambridge: Cambridge University Press, 2003.

Simon, D. M. "President, governors, and electon accountability". Journal of Politics, vol. 51, pp. 286304, 1989.

Simon, D. M.; OStRom, C. W.; MARRA, R. F. "The president, referendum voting, and subnational elections in the United States". American Political Science Review, vol. 85, no 4, p. 1.177-1.192, 1991.

Singer, A. "Raízes sociais e ideológicas do lulismo". Novos Estudos, no 85, p. 83-102, 2009.

WeYLAND, K. "Peasants or bankers in Venezuela? Presidential popularity and economic reform approval, 1989-1993". Political Research Quarterly, vol. 51, n 2, p. 341-362, 1998.

Zucco JR., C. "The presidents 'new' constituency: Lula and the pragmatic vote in Brazil's 2006 presidential election". Journal of Latin American Studies, vol. 40, no 1, p. 29-49, 2008.

. "When payouts pay off: conditional cash transfers and voting behavior in Brazil 2002-2010". American Journal of Political Science, vol. 57, no 4, p. 810-822, 2013. 


\section{ANEXOS}

\section{Anexo 1}

Partidos incumbentes por estado (2010-2014)

\begin{tabular}{|c|c|c|}
\hline Estado & 2010 & 2014 \\
\hline$A C$ & PT & PT \\
\hline $\mathrm{AL}$ & PSDB & PSDB \\
\hline$A M$ & PMN & PROS \\
\hline AP & PSB & PSB \\
\hline BA & PT & PT \\
\hline CE & PSB & PT \\
\hline DF & PT & PT \\
\hline ES & PSB & PSB \\
\hline GO & PSDB & PSDB \\
\hline MA & PMDB & PMDB \\
\hline MG & PSDB & PSDB \\
\hline MS & PMDB & PMDB \\
\hline MT & PMDB & PT \\
\hline PA & PSDB & PSDB \\
\hline PB & PSB & PSB \\
\hline PE & PSB & PSB \\
\hline PI & PSB & PMDB \\
\hline PR & PSDB & PSDB \\
\hline RJ & PMDB & PMDB \\
\hline $\mathrm{RN}$ & DEM & PSD \\
\hline RO & PMDB & PMDB \\
\hline $\mathrm{RR}$ & PSDB & PSB \\
\hline RS & PT & PT \\
\hline SC & DEM & PSD \\
\hline SE & PT & PMDB \\
\hline SP & PSDB & PSDB \\
\hline TO & PSDB & SDD \\
\hline
\end{tabular}

Fonte: Elaboração própria com dados do TSE. 
Anexo 2

Lista de estados em que os partidos lançaram candidatos (2014)

\begin{tabular}{|c|c|c|}
\hline PMDB & PSDB & PT \\
\hline AL & AC & AC \\
\hline AM & AL & BA \\
\hline CE & DF & CE \\
\hline ES & GO & DF \\
\hline GO & MG & ES \\
\hline MA & MS & GO \\
\hline MS & PA & MG \\
\hline PA & PB & MS \\
\hline PB & PR & MT \\
\hline PI & RO & PI \\
\hline PR & SC & PR \\
\hline RJ & SP & RJ \\
\hline RN & & RO \\
\hline RO & & RR \\
\hline SE & & RS \\
\hline SP & & SC \\
\hline TO & & SP \\
\hline
\end{tabular}

Fonte: Elaboração própria com dados do TSE.

\section{Resumo}

Como os brasileiros escolhem os governadores? Desvendando as razões do voto para os executivos estaduais no Brasil em 2014

Apesar da importância das disputas para os governos estaduais na política brasileira, pouco se sabe a respeito dos fatores que levam às escolhas dos eleitores para esses pleitos. Existem fatores comuns que ajudam a explicar a escolha dos eleitores em todo o país para os governos estaduais? Qual é o peso da avaliação do governo federal e da percepção sobre o desempenho da economia do país nas eleições nas unidades da federação? Candidatos à reeleição ou apoiados pelo governador são beneficiados pela avaliação positiva do governo federal? A preferência partidária importa na hora de escolher os candidatos a governador? Essas são as perguntas que buscamos responder, ainda que de maneira preliminar, neste artigo. Para isso, realizamos análises multivariadas a partir dos dados de nível individual produzidos pelo Estudo Eleitoral Brasileiro (Eseb) de 2014. Os resultados indicam que a 
preferência partidária, assim como nas eleições presidenciais, é importante elemento de escolha nos pleitos para os governos estaduais, e que a disputa entre PT e PSDB no plano nacional acaba por influenciar também o âmbito estadual.

Palavras-chave: comportamento eleitoral; eleições 2014; governos estaduais

\begin{abstract}
How do Brazilians choose their governors? An attempt at understanding the electoral behavior in the gubernatorial elections in Brazil in 2014

Despite the importance of elections for governor in Brazilian politics, we know very little about how voters behave in gubernatorial elections. Are common features capable of explaining electoral behaviour in gubernatorial races throughout the country? How do evaluations of the national government and of the economy impact these disputes? Do incumbents receive more support from those who have a positive perception of the national government? Does party identification matter? These are the questions addressed in the present work. In doing so, we have developed multivariate analyses using data from the Brazilian Electoral Study conducted in 2014. The results suggest that party identification matters and that the dispute between the PT and the PSDB at the national level also influences gubernatorial races.
\end{abstract}

Key words: electoral behaviour; elections 2014; state governments

\title{
Resumen
}

¿Cómo eligen los brasileros a sus gobernadores? Una tentativa de comprender las razones del voto para los ejecutivos estatales en Brasil en 2014

Las elecciones para los gobiernos estatales son muy importantes en la política brasileña. A pesar de eso, poco se sabe sobre los factores que influencian las decisiones de los electores en esas disputas. ¿Hay factores comunes que ayudan a explicar las opciones de los electores en todo el país para los gobiernos estatales? ¿Cuál es la importancia de la evaluación del Gobierno Nacional y de la economía en las elecciones estatales? ¿Candidatos a una reelección o apoyados por el gobernador son los beneficiados con una evaluación positiva por el gobierno federal? ¿Las preferencias partidarias importan a la hora de escoger los candidatos a gobernador? Esas son las preguntas que intentamos contestar de forma preliminar en este artículo. Para eso, realizamos análisis multivariantes con datos del Estudio Electoral Brasilero de 2014. Los resultados indican que las preferencias partidarias y la disputa entre el PT y el PSDB en el plan nacional tienen influencia en las elecciones para los ejecutivos estatales.

Palabras clave: comportamiento electoral; elecciones 2014; gobiernos estatales

\section{Résumé}

Comment les Brésiliens choisissent-ils les gouverneurs? Retour sur les raisons du vote en faveur des dirigeants des États fédérés au Brésil en 2014

Malgré l'importance, dans la politique brésilienne, de pouvoir disputer les élections pour les gouvernements des états fédérés, on en sait peu quant aux facteurs qui mènent les électeurs à faire leur choix pour ces scrutins. Existent-ils des facteurs communs qui permettent d'expliquer le choix des électeurs dans le pays entier pour les gouvernements d'états fédérés? Quel est le poids de l'évaluation du gouvernement fédéral et de la perception que I'on a de la performance de l'économie du pays dans les élections, dans ces unités de la fédération? Des candidats à la réélection ou soutenus pour le gouverneur sont-ils favorisés par l'évaluation positive du Gouvernement Fédéral? La préférence partisane compte-t-elle au moment de choisir les candidats au poste de gouverneur? Voici les questions auxquelles nous avons cherché à répondre, bien que d'une façon préliminaire, dans cet 
article. Pour cela, nous avons réalisé des analyses multivariées, à partir de données au niveau individuel, produites par l'Étude Électoral Brésilienne (Eseb) de 2014. Les résultats indiquent que la préférence partisane, de même que dans les élections présidentielles est un choix important pour les élections des gouvernements d'état, et que le conflit entre le PT et le PSDB au niveau national a aussi de I'influence au niveau des états fédérés.

Mots-clés: comportement électoral; élections 2014; gouvernements d'état

Artigo submetido à publicação em março de 2016. Versão final aprovada em novembro de 2016. 